\title{
Development of Basic Adaptive Model of the Real Property Item as a Support System for the Development Project
}

\author{
Violetta Politi ${ }^{1, *}$ \\ ${ }^{1}$ Moscow State University of Civil Engineering,26, Yaroslavskoye shosse, Moscow,129337, Russia
}

\begin{abstract}
The article describes the method of the detailed description of the item, as a basic managed element of the real estate development project. A mathematical adaptive model of development, which can influence on right organizational-managerial decision-makings on the stage of pre-investment research, was proposed on the basis of consideration of the set of characteristics and diversified features of the item, as well as its ability to self-development. The result of the work can be used as the base model in the design of decision support system in the initiation of the development project.
\end{abstract}

\section{Introduction}

Currently, the issue of effective management of development projects at the stage of the investment decision initiation is of particular importance. At the same time, forecasts of experts are the main economic instrument for the developer's adoption of an effective management decision. At this stage, the goals, the forecasted level of profitability of investments, the possibility of using the instrument of the public private partnership are precisely defined. Reliability of economic assessment largely determines the availability of decision support system, which is designed to take into account the changes in the real estate item at each stage of the project. To ensure the development process using modern tools and software, the mathematical model of the property item must be built, and namely, the set of fixed and time-varying characteristics of the item that are essential for the successful implementation of the development project must be formally described.

\section{Methods}

Firstly, the property item is the physical asset; secondly, it is the subject of economic relations and; thirdly, the subject of legal relations. The fourth characteristic can also be added, if we take into account the land resources, and the fact that a property item is also the subject of social relations.

It can be concluded that the property item has a great number of essential characteristics. In constructing the model, the dynamics of the real estate market, and the

*Corresponding author: polity_violca@list.ru 
variability of the market subject preferences should be taken into account. Furthermore, the redundancy of the property item characteristics must be avoided. Therefore, in order to construct an adequate mathematical model it must be fitted with the adaptive flexibility to inevitable changes in the economic environment [1].

Many features of the property item must satisfy the following conditions: completeness, measurability, consistency, minimality and independence; performance of decomposition conditions. Principal subjects of the real estate market that could affect the status of the property item can be represented as a kind of a set $M^{\text {objekt }}$ that includes foreign and domestic investors; developers; contractors; owners; customers; tenants; and appraisers.

Thus, the set consists of the following elements:

$$
M^{\text {subjekt }}=\left\{\begin{array}{l}
I-\text { investment } ; D-\text { developers } ; C-\text { constructors } ; \\
O-\text { owers } ; B-\text { buers } ; R-\text { renders } ; A-\text { appraisers }
\end{array}\right\}
$$

The basic characteristics of an item which is conditioned upon its belonging to one of three classes of property are changing in the course of the real estate development project implementation: residential property items; non-residential property items; land plots [2].

These classes of urban real estate defined by cardinal functional feature, can also be represented as a set $M^{\text {item }}$, and then the symbols of all the elements of this set should be entered:

$$
\begin{aligned}
& M_{1}^{\text {item }} \text { - residentialpropertyitems; } \\
& M_{2}^{\text {item }} \text { - non - residentialpropertyitems; } \\
& M_{3}^{\text {item }} \text { - landplots; }
\end{aligned}
$$

Then we can write as follows:

$$
\begin{aligned}
& M^{i t e m}=M_{1}^{i t e m}+M_{2}^{i t e m}+M_{3}^{i t e m} \\
& M_{i}^{i t e m} \cap M_{j}^{i t e m}=\mathrm{e}, \text { wherei } \neq j
\end{aligned}
$$

Let the level of detail of the above elements of a set $M^{\text {item }}$ be defined. Therefore, the sets $M_{i}^{i t e m}, i=1,2,3$ are informatively describable, because they are the finite ones.

$$
M_{i}^{i t e m}=N_{i},(i=1,2,3) \Rightarrow M_{i}^{i t e m}=\left\{m_{i}^{1}, m_{i}^{2}, \ldots, m_{i}^{n},\right\},
$$

where $N_{i}$ - the number of elements of the set $M_{i}^{i t e m} ; m_{i}^{n}\left(n=1,2, \ldots N_{i}\right)$ - the elements of the set $M_{i}^{i \text { tem }}(i=1,2,3)$.

Note 1. Concerning the identification and taking into account of the specific characteristics of a particular property item.

There exists a function $\Lambda$ of the set $\mathrm{M}_{3}^{\text {item }}{ }_{\mathrm{B}} \mathrm{M}_{2}^{\text {item }}$, converting some elements of the set $\mathrm{M}_{3}^{\mathrm{item}}$ into the elements of the set $\mathrm{M}_{2}^{\mathrm{item}}$.

For example, the practical expression of this function is the conversion of industrial real estate elements into the items of commercial real estate. Therefore, the separation of items on the type functional classes itself $\mathrm{M}^{\mathrm{item}}$ is a permanent, non-permanent in time, and conditional one, especially when it is related to the implementation of projects aimed at the real estate development. The fact that the real estate item belongs to one of the classes in each phase of the development project evolution, is the identifying one [3].

The analysis of general and specific properties of the items $\left\{m_{i}^{1}, m_{i}^{2}, \ldots, m_{i}^{n}\right\}$, where $i=1,2,3$ oftheset $M_{i}^{i t e m}$, revealed that each item $m_{i}^{n}$ can be characterized by the other set of particular features. $P_{i}^{n}=\left\{p_{i}^{n 1} ; p_{i}^{n 2} \ldots ; p_{i}^{n k}\right\}$. This set, in turn, is a subset of a $U$ set of various specific properties of the real property items: 


$$
P_{i}^{n} \subset U
$$

Research in the field of real estate development has shown that a set of specific features of an item may include from sixty to eighty elements.

Note 2.Concerning the necessity of taking into account the time factor.

Both, the state of the external economic environment, and the dynamic changes in the internal conditions occurring during the real estate market $(t)$ evolution have an impact on the composition and the number of elements of the $U$ set, as well as on the properties of the real property market item. Therefore, the studied characteristics are the variables [4]. Therefore:

$$
U_{t-1} \neq U_{t}
$$

Further, let's select the following sets $P_{i}^{n 1} ; P_{i}^{n 2} ; P_{i}^{n 3} ; P_{i}^{n 4}$, consisting of legal, spatial, structural and functional and the technical and economic features of the element $m_{i}^{n}$, respectively:

$$
\begin{aligned}
& P_{i}^{n}=P_{i}^{n 1} \cup P_{i}^{n 2} \cup P_{i}^{n 3} \cup P_{i}^{n 4}, \\
& \text { wheren }=1,2, \ldots, \quad, \quad i=1,2,3,4 .
\end{aligned}
$$

Legal feature of the property item $\mathrm{P}_{\mathrm{i}}^{\mathrm{n} 1}$ is a determinant of its legal status at various stages of the development project implementation. Therefore, the transfer of land from one category to another entails the emergence of new options of its use. For example, whereas it is necessary to change the designation of a land plot in connection with its withdrawal for state or municipal needs, this land plot is converted from the one class of lands into another taking into account the peculiarities stipulated by the federal law. Before the provision of the seized land plot to the interested citizen or entity the executive authorities and local government are obliged to make its conversion from the lands of a certain category to a category, which provides for the permitted use of the land plot for its intended purpose [5].

The spatial feature of the property item $\mathrm{P}_{\mathrm{i}}^{\mathrm{n} 2}$ (or the spatial implementation of urban processes) includes consideration of factors such as the territorial location (town, street, house); architectural design and planning of residential areas and industrial districts of the city (zoning by functions; planning solutions; transport and pedestrian flows, etc.).

Structural and functional features of the property item $\mathrm{P}_{\mathrm{i}}^{\mathrm{n} 3}$ include a functional purpose; type of protective structures; engineering communications; deformations, etc.

Technical and economic features of the element $\mathrm{P}_{\mathrm{i}}^{\mathrm{n}}$ consist of the following indicators: volume and area of the building; number of floors; regulatory and operating lifetime; phase of the item life cycle; total accumulated depreciation; residual value of the item, etc.

Accounting for the time factor is expressed in the need for monitoring the change of characteristics of the U set elements. However, in consideration of these characteristics in the implementation of the development project the above elements can behave ambiguously.

Note 3.Concerning the variability particular features of the property item.

It should be noted that during any phase of the development project implementation, the following proposition will be valid for any property item: $m_{i}^{n} \in M_{i}^{\text {item }}$. Let's define the variability of particular features [6]:

- Particular features described by the set $\mathrm{P}_{\mathrm{i}}^{\mathrm{n} 1}$ (legal characteristics) may be changed;

- Particular features described by the set $\mathrm{P}_{\mathrm{i}}^{\mathrm{n} 2}$ (spacial characteristics) will remain unchanged;

- Particular features described by the set $\mathrm{P}_{\mathrm{i}}^{\mathrm{n} 3}$ (structural and functional characteristics) may be changed in the development project implementation, which should lead to an 
increase in economic benefits from the use of the item and increase of its investment attractiveness;

- Particular features described by the set $\mathrm{P}_{\mathrm{i}}^{\mathrm{n}}{ }^{\text {(technical and economic characteristics) }}$ may not be changed during the entire development project life cycle; the changes may be the result of changes in the elements of the sets $\mathrm{P}_{\mathrm{i}}^{\mathrm{n} 1} u \mathrm{P}_{\mathrm{i}}^{\mathrm{n} 3}$, in the form of increase of the property item market value.

Further, let's consider the structural and functional characteristics separately. Among the set of functional properties $\mathrm{P}_{\mathrm{i}}^{\mathrm{n} 3}$ we should allocate the subset of the primary functional properties $p_{\mathrm{i}}^{\mathrm{n} 3} \subset \mathrm{P}_{\mathrm{i}}^{\mathrm{n} 3}$, which make it possible to extend the basic classification by functional features (Table 1) [7].

Table 1.Classification of urban property items by functional features

\begin{tabular}{|c|c|c|}
\hline \multicolumn{3}{|c|}{ Set of urban property items } \\
\hline $\begin{array}{c}M_{1}^{\text {item }} \\
\text { Residentialproperty } \\
\text { items }\end{array}$ & $\begin{array}{c}M_{2}^{\text {item }} \\
\text { Non-residentialproperty items }\end{array}$ & $\begin{array}{c}M_{3}^{i \text { item }} \\
\text { Urban land plots }\end{array}$ \\
\hline Individual houses & Business and commercial facilities & $\begin{array}{l}\text { Lands for residential and } \\
\text { public construction }\end{array}$ \\
\hline Double houses & Industrial facilities & Common-use lands \\
\hline \multirow{2}{*}{$\begin{array}{l}\text { Low-rise residential } \\
\text { construction facilities }\end{array}$} & Recreational facilities & \multirow{2}{*}{$\begin{array}{l}\text { lands for industrial, } \\
\text { warehousing and storage of } \\
\text { municipal construction }\end{array}$} \\
\hline & \multirow{2}{*}{$\begin{array}{l}\text { Education, science, health, physical } \\
\text { culture and sports, arts, and religion } \\
\text { facilities }\end{array}$} & \\
\hline \multirow{2}{*}{$\begin{array}{ll}\text { Mid-rise } & \text { residential } \\
\text { buildings } & \end{array}$} & & \multirow{2}{*}{$\begin{array}{l}\text { Lands for transport, } \\
\text { communication, utilities }\end{array}$} \\
\hline & \multirow{3}{*}{$\begin{array}{l}\text { Trade, public catering, consumer } \\
\text { services, service, recreation and } \\
\text { entertainment facilities } \\
\text { Other facilities }\end{array}$} & \\
\hline \multirow[t]{2}{*}{$\begin{array}{l}\text { Multi-storey high-rise } \\
\text { residential houses }\end{array}$} & & $\begin{array}{l}\text { Lands of } \\
\text { protected areas }\end{array}$ \\
\hline & & Other lands \\
\hline
\end{tabular}

Consider the set of characteristics $P_{i}^{n}=\left\{p_{i}^{n 1}, p_{i}^{n 2}, \ldots p_{i}^{n k}\right\}$ of the item $m_{i}^{n}$. Each particular feature $p_{i}^{n j}$ (except for $p_{i}^{n j}$, wherej $=2$ ), may take one of the specific values on a given set of implementations $R_{i}^{n j}=\left\{r_{i}^{n j 1}, r_{i}^{n j 2}, \ldots r_{i}^{n j L}\right\}$, where:

$p_{i}^{n 1} \in\left\{r_{i}^{n j 1}, r_{i}^{n j 2}, \ldots r_{i}^{n j L}\right\}$.

Note 4.Concerning the accounting for the dynamics of the external environment of real estate development project.

In general, the value and number of L elements of a set $R_{i}^{n j}$ are the variables.

Note 5. The ability to transfer a single element $m_{i}^{n}$ of a set $M^{\text {objekt }}$ to the element of the set is provided by changing the elements of a set of implementations.

$R_{i}^{n j}=\left\{r_{i}^{n j 1}, r_{i}^{n j 2}, \ldots r_{i}^{n j L}\right\}$.

In order to study the properties of the real estate items and make research of its constituent elements (features), the following definitions must be applied [8].

Definition 1. The property item will be called the base one, which acts as a whole and indivisible item of the transaction (purchase/ sale/ rent), and none of its individual parts cannot be the subject of the transaction (purchase/ sale/ rent). The basic property items can be classified as the single-function and multi-function ones [9].

Definition 2. The complex property item includes a set of the base single-function items. The complex property item may act as a single subject of the transaction (purchase/ sale/ rent).

Definition 3. The complex property item includes a set of multi-functional basic property items. 


\section{Results}

In this paper, the system adaptive model of the property item was built on a theoretical and multiple levels. Pre-investment phase is one of the important phases of the development project implementation. In practice, this phase of the project initiation is mainly based on expert judgment and has an intuitive nature. Whereas, in the subsequent phases of the development project (construction and operation of the facility), the information support was provided through the software products developed and introduced to the market (Project Expert; Microsoft Project, etc.), at the decision-making stage the support was implemented by a team of experienced experts only [10].

\section{Discussion}

Scientific works, periodicals and journals have previously considered the issues of the necessity to develop a methodological apparatus for a detailed description, common characterization and assessment of the state of the managed development facility [11].

In their works, the scientists perform a critical analysis of the existing procedures and regulations for the assessment of the current state of the property item. They also note the absence of information support for the development projects at the decision-making stage, designed to ensure the reduction of the risk component of the project, and to increase the accuracy of the assessment of the results of implementation of both management and engineering, and architectural and design decisions.

\section{Conclusion}

The unavailability of a complete and structured database for making organizational and management decisions at an important stage of pre-investment study, may lead to false results associated with the assessment of investment attractiveness of the facility, and to the overestimation of the magnitude of the effect of the development project implementation. Therefore, the proposed system adaptive model was designed to be the basis for the development of methods and software to support the investment decision-making on the property item development.

\section{References}

1. I.G. Lukmanova, M.Y. Mishlanova, International Journal of Economics and Financial Issues, 5, 208-216 (2015)

2. I.G. Lukmanova, A.G. Korolev, E.V. Nezhnikova. Projects management. Study guide. Moscow (2013)

3. D.N. Silka, N.V. Scherbakova. Bulletin of the University 32. 204-209 (2009)

4. S.S. Uvarova, S.V. Belyaeva, A.A. Panenkov, MSUCE Vestnik, 4, 130-139 (2016)

5. E.M. Kiseleva, M.L. Nekrasova, M.A. Mayorova, M.N. Rudenko, V.S Kankhva, International Review of Management and Marketing. 6, 95 (2016)

6. K.M. Gumba, V.U. Mikhailov, V.V. Gamuletskiy. Formation of the mechanism of innovative-strategic development of construction enterprises, MGSU (2012)

7. S.S. Uvarova, V.S. Kankhva, S.V. Belyaeva. Economic stability of construction enterprises and projects, MGSU (2011) 
8. H. Hottenrott, S. Rexhäuser, Original Research Article Resource and Energy Economics, 43, 172-194 (2016)

9. I. Hyvär,Procedia - Social and Behavioral Sciences, 226, 108-115 (2016)

10. R. Lozano, K. Ceulemans, S. ScarffSeatter, Journal of Cleaner Production, 106, 205215 (2015)

11. I.G. Lukmanova, N.Y. Yaskova, Economikastroitelstva, 5, 13 (2014) 